\title{
(6) OPEN ACCESS \\ Better drug use in advanced disease: an international Delphi study
}

\author{
Bregje A. A. Huisman, ${ }^{1}$ Eric C. T. Geijteman, ${ }^{2,3}$ Marianne K. Dees, ${ }^{4}$ \\ Lia van Zuylen, ${ }^{2}$ Agnes van der Heide, ${ }^{3}$ Roberto S.G.M. Perez ${ }^{1}$
}

- Additional material is published online only. To view please visit the journal online (http://dx.doi.org/10.1136/ bmjspcare-2018-001623).

'Department of Anesthesiology, VU University Medical Center, Amsterdam, The Netherlands ${ }^{2}$ Department of Medical Oncology, Erasmus MC Cancer Institute, Erasmus University Medical Center, Rotterdam, The Netherlands

${ }^{3}$ Department of Public Health, Erasmus University Medical

Center, Rotterdam, The

Netherlands

${ }^{4}$ Radboud Institute for Health Sciences, IQ healthcare, Radboud University Medical Center, Nijmegen, The Netherlands

\section{Correspondence to}

Drs. Bregje A. A. Huisman, Department of Anesthesiology, VU University Medical Center, Amsterdam 1081 HV, The Netherlands;

b.huisman@vumc.nl

Dr Roberto Perez died on 7 September 2017

Received 27 July 2018 Revised 24 October 2018 Accepted 1 November 2018

\section{Check for updates}

(c) Author(s) (or their employer(s)) 2018. Re-use permitted under CC BY-NC. No commercial re-use. See rights and permissions. Published by BMJ.

\footnotetext{
To cite: Huisman BAA, Geijteman ECT, Dees MK, et al. BMJ Supportive \& Palliative Care Epub ahead of print: [please include Day Month Year]. doi:10.1136/ bmjspcare-2018-001623
}

\section{ABSTRACT}

Patients with a limited life expectancy use many medications, some of which may be questionable.

Objectives To identify possible solutions for difficulties concerning medication management and formulate recommendations to improve medication management at the end of life.

Methods A two-round Delphi study with experts in the field of medication management and end-of-life care (based on ranking in the citation index in Web of Science and relevant publications). We developed a questionnaire with 58 possible solutions for problems regarding medication management at the end of life that were identified in previously performed studies.

Results A total of 42 experts from 13 countries participated. Response rate in the first round was $93 \%$, mean agreement between experts for all solutions was $87 \%$ (range 62\%$100 \%)$; additional suggestions were given by $51 \%$. The response rate in the second round was $74 \%$. Awareness, education and timely communication about medication management came forward as top priorities for guidelines. In addition, solutions considered crucial by many of the experts were development of a list of inappropriate medications at the end of life and incorporation of recommendations for end-of-life medication management in diseasespecific guidelines.

Conclusions In this international Delphi study, experts reached a high level of consensus on recommendations to improve medication management in end-of-life care. These findings may contribute to the development of clinical practice guidelines for medication management in end-of-life care.

\section{INTRODUCTION}

Patients with a limited life expectancy often use many medications, including medication prescribed for long-term prevention and for the treatment of comorbidities. ${ }^{1-4}$ When the end of life approaches, all medications should be reconsidered taking into account their (potential) beneficial and adverse effects, burden of administration and their costs. Physicians, nurses, patients and their relatives agree that inappropriate medications should be discontinued at the end of life. ${ }^{5}$ However, deprescribing is a complex process, and in clinical practice, a medication review and timely discontinuation of potentially inappropriate medications (PIMs) is not self-evident. ${ }^{6}$

Recommendations have been formulated for (dis)continuing PIMs at the end of life, such as antihyperglycemic agents, antimicrobials, cholinesterase inhibitors and bisphosphonates. ${ }^{78}$ Several guidelines are available to support physicians with medication management in patients with life-limiting disease. ${ }^{10}$ However, significant barriers still impede adequate medication management. Physicians seem to have a limited awareness of the issue and report a variety of reasons for not considering withdrawal of PIMs, which include low priority, uncertainty about the consequences and avoiding confronting patients with their impending death. ${ }^{11}$ Apart from physician-related barriers, prominent barriers subsist on the level of the organisation of healthcare and in communication and collaboration between healthcare prioviders. ${ }^{12}$

To improve adequate medication management in patients with advanced disease, better interventions and evidence are needed. ${ }^{12}$ The perspectives on medication management and priorities in end-of-life care of patients, their relatives, nurses and physicians, their roles in decision making, organisational aspects and communication should be taken into account. ${ }^{5}$ The aim of this study was to identify and prioritise possible solutions for the key impediments and to formulate recommendations to 
improve medication management at the end of life. We consulted international experts in pharmacology and end-of-life care and performed a Delphi study.

\section{METHODS}

This study was conducted within the MEDIcation management in the LAST phase of life (MEDILAST) project. MEDILAST is a multicentre mixed-methods research project with the objective of understanding current medication use in the last 3 months of life and the associated process of decision making and formulating recommendations to optimise medication management in end-of-life care. The project is carried out in a collaboration of VU University Medical Center, Erasmus University Medical Center and Radboud University Medical Center in the Netherlands.

\section{Experts}

A two-round Delphi survey was conducted among experts in the field of medication management and end-of-life care. Considering the scope of this Delphi procedure, we sought experts with a clear track record in palliative care and experts with a relevant background in medication management in care for the elderly. We aimed to include experts with different professional backgrounds in order to account for the multidisciplinary nature of palliative care. The selection of experts was based on ranking in the citation index in Web of Science (search: Palliative Care/Terminal Care/Hospice Care AND Medication/ Drug Utilization/Inappropriate Prescribing/Drug Prescriptions/Polypharmacy) and relevant publications regarding medication management. In addition, experts from the Dutch multidisciplinary guideline on polypharmacy in elderly, ${ }^{13}$ palliative care practice guidelines $^{14}$ and palliative care expertise centers ${ }^{15}$ in the Netherlands were invited to participate. We aimed for an expert panel of about 40 experts. We used purposive sampling to ensure diversity of background and nationality. Experts who did not respond received a reminder e-mail 4 weeks after sending the original invitation. In total, 76 experts were invited, until at least 40 participants had given their written consent.

\section{Questionnaire and study design}

From literature and previous studies in our MEDILAST project (medical record review, in-depth interviews and a questionnaire study), barriers for adequate medication management at the end of life were identified. ${ }^{5} 1116$ Based on these findings, we formulated possible solutions addressing these barriers. The solutions were reviewed internally by our project group (that consists of a general practitioner (MD), internal medicine resident and clinical pharmacologist (EG), medical oncologist (LZ), anesthesiologist (BH), medical doctor-philosopher (WJM Dekkers) and two researchers in palliative care (AvdH and RP)) and pilot tested among colleagues, forming a list of statements
Box 1 Definitions of concepts used in the questionnaires

Medication management: patient-centred care to optimise safe, effective and appropriate use of prescription and overthe-counter drugs.

Medication review: an assessment of the pharmacotherapy based on a structural and critical evaluation of the medical, pharmaceutical and clinical information.

End of life: the last 3 months of life.

Patient and/or family: indicating the family especially when the patient is not mentally competent.

Palliative care specialist: physician or nurse specialist/ practitioner with a formal training in palliative care medicine or equivalent expertise due to clinical experience. (added in round 2)

or recommendations. These were divided in the seven domains that were identified in our interview study ${ }^{5}$ : awareness and organisation (5 solutions), education (8), research and development (8), tools (2), roles (18), decision making (7) and communication (10) (see online supplementary appendix 1). Participants were provided with definitions of central concepts in this study (see box 1).

The Delphi study was performed in 2015. The first round questionnaire included 58 possible solutions. The experts were asked if they agreed or disagreed with the solutions, or they could tick 'no answer'. Participants were asked to suggest modifications or additional solutions. Besides, experts were requested to answer eleven questions concerning their background.

The second round questionnaire was also reviewed within the project group. This questionnaire consisted of two parts. First, the list of solutions that resulted from round 1 was presented, including the items additionally suggested or adapted by the experts. The participants were then requested to give a top 10 ranking score of the solutions they considered most relevant to formulate guidelines for medication management in end-of-life care (most relevant as number 1; two for next most relevant and so on). Second, the solutions discarded in the first round were presented. Experts could indicate if they agreed with rejection of these solutions, or whether they considered them crucial for guidelines about medication management at the end of life.

The questionnaires were sent by electronic mail. Experts were asked to respond within 4 weeks for the first round and within 6 weeks for the second round. A reminder was sent in the case of non-response within the given time range.

\section{Data processing}

The data were processed using MS Excel 2010 (Microsoft Corporation, Redmond, Washington, USA). We defined the first round cut-off value for inclusion in the second round questionnaire as agreement of $75 \%$. 


\section{Invitation of experts}

76 experts in palliative care and/or medication management in care for elderly invited $\rightarrow 42$ experts participated

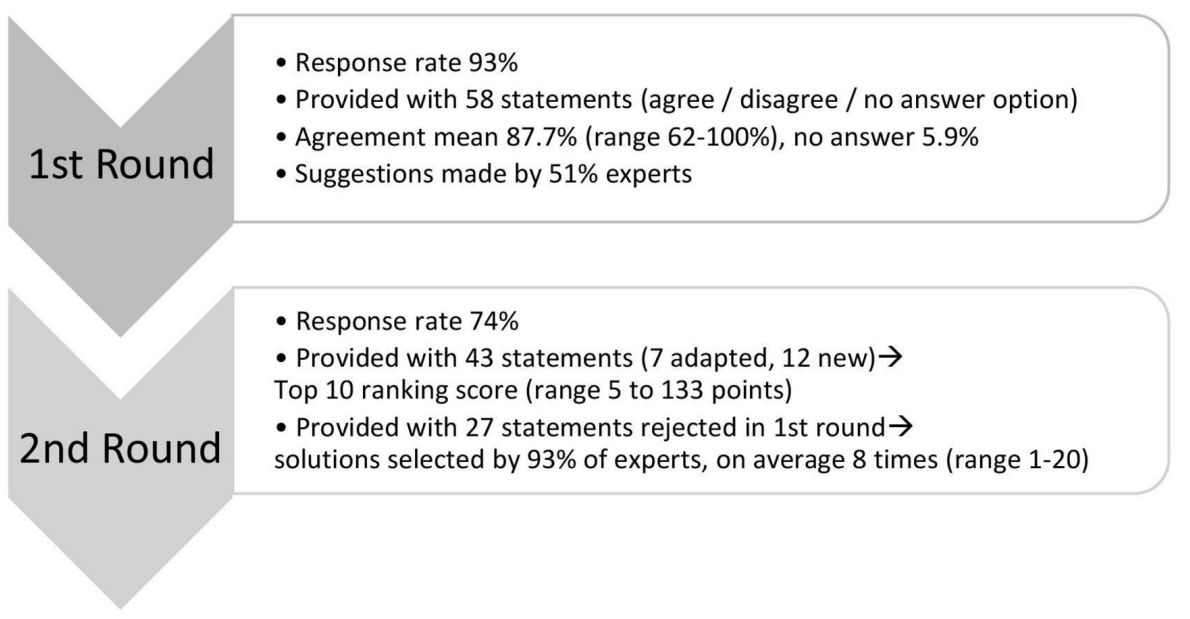

Figure 1 Flow chart of the Delphi procedure.

Based on the top 10 ranking score given in the second round, a priority score was calculated (10 points for the first, 9 points for the second and so on) for each solution to provide a ranked rating of the most important solutions as suggested by the experts.

\section{RESULTS}

Figure 1 shows a flow chart of the Delphi process. In total, 76 experts were invited. Two invitations were returned by the recipient's mail server as undeliverable, 8 experts were not available or on leave, 2 considered themselves not an expert in the field, 2 had no time, 2 refused because of a possible conflict of interest and 18 did not respond. Forty-two experts agreed to collaborate in our Delphi study.

\section{Round 1}

The response rate was $93 \%$ (39 out of 42). The respondents had a mean age of 53 years (range 35-59 years) and a mean working experience of 19 years (range 4-41 years). In addition, they originated from the Netherlands $(n=19)$, Argentina $(n=1)$, Australia $(n=2)$, Brazil $(n=1)$, Czech Republic $(n=1)$, Germany $(\mathrm{n}=2)$, Israel $(\mathrm{n}=1)$, Italy $(\mathrm{n}=1)$, Northern Ireland $(n=1)$, Norway $(n=1)$, Slovenia $(n=1)$, Sweden $(n=2)$ and the USA $(\mathrm{n}=5)$. Of one expert, the nationality was unknown. Different specialties were represented: family medicine, nursing care, geriatrics, elderly care, cardiology, oncology, pulmonology, anesthesiology, neurology, psychiatry, pharmacy, pharmacology and palliative medicine. Moreover, ethicists, researchers and medical advisors participated. The mean level of agreement for 58 statements was $87.7 \%$ (median
$89.7 \%$, range 62\%-100\%, SD 9.2, IQR 10.3). 'No answer' was selected by a mean of $5.9 \%$ (range $0 \%-20.5 \%)$. Suggestions were given by $51.3 \%$ of the experts, ranging from new statements, general comments or experiences to adjustment of solutions or the vocabulary.

Because the degree of agreement was much higher than expected, we adjusted the cut-off value for selection of statements for the second round to the mean agreement found in this first round. Thirty-one solutions exceeded this new cut-off point $(87.7 \%)$. For seven of these statements, the wording was slightly adapted based on suggestions of the participants. Based on the comments in the first round a definition of palliative care specialist was added in the second questionnaire (see box 1). Twenty-seven solutions were deleted in the second questionnaire and 12 additional solutions were presented (see online supplementary appendix 2).

\section{Round 2}

The response rate in the second round was 74\% (29 experts). One participant was on leave, one withdrew consent and eight experts did not respond. Only 2 out of 43 solutions were not included in the ranking by any of the experts. The scores calculated for the different solutions ranged from 5 to 133 (mean 36.8, median 28). The solutions with a score above the average are presented in table 1 . The experts graded solutions concerning roles, awareness, education and communication as most important.

Experts indicated that the physicians should primarily discuss the end of life and wishes, treatment goals and priorities regarding medication management 
at the end of life with the patient. Awareness is considered crucial: medication management should be an integral part of end-of-life care and be performed duly. Participants agree that this should be an individualised process, based on the patient's clinical situation. Moreover, they agreed that palliative care specialists should be available for consultation.

Specific domains that should be addressed in the education of healthcare professionals were mentioned. Physicians should be trained in communication with patients and their family about medication management at the end of life. Furthermore, education in pharmacological treatment of symptoms at the end of life was considered necessary. Accordingly, education in medication management at the end of life should be part of healthcare professionals training, in residencies, fellowships, medical schools and in nursing schools. Besides, such education should also become available for healthcare professionals. The main concern regarding communication was that it should include conversations about the goals of end-of-life care in relation to quality of life.

Twenty-seven out of 29 experts selected one or more of the 27 solutions that were initially rejected in the first round. Solutions considered crucial for guidelines about medication management by more than one-third of the experts are presented in table 2.

Participants most frequently prioritised solutions regarding research and development, awareness, education and roles. Specific suggestions for research and development included incorporation of recommendations for medication management at the end of life in disease-specific clinical practice guidelines and development of a list of medications that could be tapered or discontinued at the end of life. Regarding awareness, the experts stressed that physicians lacking experience with medication management at the end of life should consult a palliative care specialist. Explicit identification of the last phase of life was added as a focus for education for healthcare professionals. They stated that the primary treating physician is responsible for recording the medication management and for formulating an end-of-life care plan with the patient. For patients residing at home, the general practitioner is considered to be the primary treating physician. Nurses should have a supportive role by providing information, explanation and advice to the patient and relatives.

\section{DISCUSSION}

This Delphi study shows that experts in palliative care and medication management from different professions in 13 countries agree on the most important issues concerning medication management at the end of life. Key solutions indicated by the experts concern the central role of the physician in medication management, necessity of awareness on medication management at the end of life, the need for education on medication management for healthcare workers and trainees and the importance of timely communication with the patient and family in the process of medication management.

\section{Main findings}

Physicians' awareness of medication management

This Delphi study makes clear that, according to experts, the physician has a central role in medication management at the end of life. Two highly ranked solutions indicate that it is up to the physicians to discuss the medication and do this evaluation with patients in a timely manner. The urge for attention on a medication review and discussion with the patient is in line with several studies indicating the high prevalence of PIMs used by patients at the end of life. ${ }^{2} 17$ Physicians do affirm that patients at the end of life use too many medications and that they should not use PIMs ${ }^{18}$ but apparently discontinuation of PIMs is still not standard practice. As Anderson et al discuss in their study, awareness on PIMs refers to the level of insight a prescriber has into the appropriateness of his or her prescribing. They found that poor insight was an observed rather than reported barrier and that prescriber beliefs at a population level did not necessarily translate to prescribing practices for the individual patient. ${ }^{19}$ Similar findings came forward in an interview study on views of patients, relatives, nurses and physicians on medication management at the end of life. ${ }^{5}$ Although all involved parties agreed that PIMs should be discontinued and that in this process physicians should take the lead, a medication review was generally not a matter of course. These findings, altogether with the five recommendations of the experts of this Delphi study regarding education, urgently call for education on medication management in end-oflife care.

\section{Timely communication}

Multiple factors are described in literature as deprescribing barriers explaining the discrepancy between the ideal situation and practice, like lack of time, established beliefs in the benefits and harms of medication use, unknown consequences of withdrawing medications and avoidance of negative consequences. ${ }^{5} 20$ Even more importantly, physicians need to recognise a limited life expectancy of their patient and initiate end-of-life conversations as a prerequisite for decision-making conversations. ${ }^{21}$ Hancock et al describe that many healthcare professionals express discomfort at having to broach the topic of a limited prognosis and may withhold information or not disclose prognosis. These difficulties perceived by healthcare professionals in regard of speaking to patients with limited life expectancy may act as a barrier towards discontinuing medication. ${ }^{2}$ Conforming to these barriers in communication, experts in our Delphi study stress the importance of communication with 


\begin{tabular}{|c|c|c|}
\hline & Solution & Score \\
\hline 1 & $\begin{array}{l}\text { Physicians should discuss the wishes, treatment goals and priorities regarding medication management at the end of life with the } \\
\text { patient in a timely manner. (Roles) }\end{array}$ & 133 \\
\hline 2 & A medication review should be an integral part of the care for patients at the end of life. (Awareness) & 130 \\
\hline 3 & Physicians should discuss the end of life with the patient in a timely manner. (Roles) & 90 \\
\hline 4 & $\begin{array}{l}\text { Medication management at the end of life should be individualised, based on the patient's clinical situation. (Awareness - newly } \\
\text { added in round 1) }\end{array}$ & 89 \\
\hline 5 & $\begin{array}{l}\text { Healthcare professionals should be trained in communicating with patients and/or their family about decision making on medication } \\
\text { management at the end of life. (Education) }\end{array}$ & 74 \\
\hline 6 & $\begin{array}{l}\text { Education in medication management at the end of life should be incorporated in all medical training (nursing school, medical } \\
\text { students, residencies and fellowships). (Education - newly added in round 1) }\end{array}$ & 71 \\
\hline 7 & $\begin{array}{l}\text { It should be discussed with the patient and/or family that the goal of medication management at the end of life is improving/ } \\
\text { maintaining the quality of life. (Communication) }\end{array}$ & 70 \\
\hline 8 & Education in medication management at the end of life should be organised for healthcare professionals. (Education) & 61 \\
\hline 9 & Healthcare professionals should be trained in the pharmacological treatment of symptoms at the end of life. (Education) & 60 \\
\hline 10 & $\begin{array}{l}\text { Palliative care specialists should be available for consultation regarding medication management for patients at the end of life. } \\
\text { (Awareness) }\end{array}$ & 56 \\
\hline 11 & A list of drugs with a high risk of inappropriateness at the end of life should be developed. (Research) & 54 \\
\hline 12 & $\begin{array}{l}\text { In communicating about medication management at the end of life nurses and physicians should take into account the norms and } \\
\text { values of the patient and/or family. (Communication) }\end{array}$ & 52 \\
\hline 13 & $\begin{array}{l}\text { It should be discussed with the patient and/or family how the medication can be adjusted at the end of life and what can be } \\
\text { expected of these changes. (Communication) }\end{array}$ & 37 \\
\hline 14 & $\begin{array}{l}\text { Patient or proxy based assessment tools (eg, ESAS, EORTC, symptom diary, PPS and PPI) should be used to aid symptom assessment } \\
\text { and treatment at the end of life. (Tools) }\end{array}$ & 36 \\
\hline 14 & $\begin{array}{l}\text { At the end of life each drug should be revised for its potential congruence with the clinical aims of the specific situation in a specific } \\
\text { patient. (Research - newly added in round 1) }\end{array}$ & 36 \\
\hline
\end{tabular}

patients and/or their family about decision making on medication management at the end of life and the need for training of healthcare professionals specifically in communication concerning this topic.

\section{Strengths and limitations}

A strength of our study is the systematic and rigorous approach adopted in this Delphi procedure ${ }^{22}$ and the inclusion of views of experts from all over the world and coming from primary care, hospital and hospice care. The response was satisfactory, namely $93 \%$ in the first Delphi round and 74\% for the second round.
There were some limitations. First, since half of the consulted experts were Dutch, solutions may have been biased towards those relevant for the healthcare system in the Netherlands. However, in both rounds of the Delphi study, there appeared to be a high degree of consensus among all experts. Although experts of different professions participated and the average length of working experience (19 years) suggests that our panel represents a broad and experienced group, it is not possible to determine if the panel is

Table 2 First round solutions selected by more than one-third of experts not to be rejected Solution

1 In current treatment guidelines (eg, for hypertension, heart failure and diabetes) recommendations for medication management at the 20 end of life should be incorporated. (Research)

2 A list of drugs that could be tapered off or discontinued at the end of life under certain conditions should be developed (eg, anticoagulant, antihypertensive, blood glucose lowering, antibiotic, antipsychotic, antidepressant or anticonvulsive drugs). (Research)

3 Physicians lacking experience with medication management at the end of life should consult a palliative care specialist. (Awareness) 16

$4 \quad$ Marking of the end of life should be part of education for healthcare professionals. (Education) 12 The primary treating physician should formulate an end-of-life care plan with the patient and/or family. (Roles) 12 The general practitioner is the primary treating physician when the patient resides at home. (Roles)

$5 \quad$ The primary treating physician is responsible for recording the medication management at the end of life. (Roles) 10 Nurses should contribute to medication management at the end of life by providing information, explanation and advice to the patient 10 and/or family. (Roles) 
representative of the population of palliative care and medication management experts.

Second, a pre-Delphi survey or focus group might have contributed to prepare the first survey of our Delphi study to address the study aim. Third, the consensus for the first round was predefined as $75 \%$ agreement, a cut-off common according to acknowledged Delphi guidelines. ${ }^{23}$ The high degree of consensus in our study $(87.7 \%)$ drove us to redefine the cut-off point. The exact limit could be a matter of discussion.

Finally, the definition of palliative care specialist (box 1) does not allow for specialist palliative care pharmacists or other healthcare professionals who have an integral role in medication management at end of life.

\section{What this study adds}

Before starting the MEDILAST project, no comprehensive evidence-based guidelines for medication management in end-of-life care were available. ${ }^{24}$ Many tools and guidelines are available to manage medication for the aged, for example, the Beers criteria, ${ }^{25} 26$ STOPP (Screening Tool of Older Person's Prescriptions) and START (Screening Tool to Alert doctors to Right Treatment) criteria ${ }^{27}$ and the Medication Appropriateness Index. ${ }^{28}$ Meanwhile, the OncPal deprescribing guideline ${ }^{9}$ and Screening Tool of Older Persons Prescriptions in Frail adults with limited life expectancy (STOPPfrail) ${ }^{10}$ were published. Lindsay et al developed the OncPal deprescribing guideline to assist in discontinuation of specific medications or medication classes (like aspirin, dyslipidaemia medications and antihypertensives) in patients with advanced cancer. ${ }^{9}$ Lavan and colleagues ${ }^{10}$ published the STOPPfrail, a list of 27 criteria determined in a Delphi consensus survey. The criteria relate to medications that are potentially inappropriate in frail older patients with limited life expectancy and may assist physicians in deprescribing medications in these patients. Our Delphi study indicates that translation of these tools into practice as a deprescribing guideline will also need to address the other steps of the deprescribing process, like communication about treatment goals, planning medication withdrawal (tapering if required), monitoring and follow-up after cessation.

Experts in our study gave specific suggestions for research and development. Whereas a substantial part of medications in end-of-life care are prescribed for comorbid diseases, ${ }^{16}$ there is an urge for reflection on how to manage those medications at the end of life and to address this issue in treatment guidelines. Pharmacological guidelines rarely give any recommendations for discontinuation. Experts in our study suggested research investigating discontinuation or tapering off medications at the end of life under certain conditions, for example, in chronic conditions like diabetes and cardiovascular disease. Koekkoek et $a l^{29}$ give a good example of how to deal with oral anticonvulsants in the end of life of patients with glioma who develop swallowing difficulties. Although this applies to a very specific patient group, their suggestions could be extrapolated to other populations.

\section{CONCLUSIONS}

Experts in the field of medication management and end-of life care from 13 countries reached a high level of consensus on a number of important recommendations to improve medication management at the end of life. Key issues indicated by the experts concern the central role of the physician in medication management, necessity of awareness on medication management at the end of life; the need for education on medication management for healthcare workers and trainees; and the importance of communication with the patient and family in the process of medication management. These indications complement the elements provided in the existing tools for medication management. Research is needed to facilitate medication management in end-of-life care to develop a list of medications inappropriate in end-oflife care and incorporation of recommendations for end-of-life medication management in disease-specific guidelines. A best practice for medication management in end-of-life care including specific guidelines for particular medications and recommendations regarding decision making and communication should be elaborated.

Acknowledgements The authors would like to thank the international experts for their participation in this Delphi study: Meera Agar, Kevin Bain, Claudia Bausewein, Louise Bellersen, Eduardo Bruera, Marjolein Bannink, Massimo Costantini, Robert van Dongen, Dagny Faksvåg Haugen, Doron Garfinkel, Alexander de Graeff, Herbert Habets, Steven Handler, Joseph Hanlon, Deon Hayley, Holly Holmes, Carmel Hughes, Tiny Jaarsma, Paul Jansen, Daisy Janssen, Anne Mieke Karsch, Gerrit Kimsma, Raymond Koopmans, Rob Krol, Urška Lunder, Friedemann Nauck, Gert Olthuis, Rachel Riechelmann, James Stevenson, Vilma Tripodoro, Ragnhild Vrijaldenhoven-Haitsma and Zbigniew Zylicz. Their participation in this study does not necessarily mean that they fully agree with the final conclusions. We would like to thank Wim Dekkers for his contribution to the study.

Contributors All authors conceived the study. All authors contributed to the study planning and design. BH contributed to data collection. $\mathrm{BH}$ analysed and interpreted the data with input from RP, AvdH, LvZ, EG and MD. BH wrote the manuscript with input and feedback from RP, AvdH, LvZ, EG and MD.

Funding This research study was undertaken within the framework of the Medication Management in the Last Phase of Life project which is funded by a grant from the Dutch government (ZonMw 80-82100-98-210).

Disclaimer The opinions expressed are those of the authors. The funding party did not influence any aspect of the study design, collection, analysis or interpretation of data, or decision to submit the manuscript for publication.

Competing interests None declared.

Patient consent Not required. 
Ethics approval The study was reviewed by the Medical Ethics Review Committee of the VU Medical Center and does not fall under the scope of the Medical Research Involving Human Subjects Act. All participants provided informed consent and received written information about the study.

Provenance and peer review Not commissioned; externally peer reviewed.

Open access This is an open access article distributed in accordance with the Creative Commons Attribution Non Commercial (CC BY-NC 4.0) license, which permits others to distribute, remix, adapt, build upon this work noncommercially, and license their derivative works on different terms, provided the original work is properly cited, appropriate credit is given, any changes made indicated, and the use is noncommercial. See: http://creativecommons.org/licenses/by-nc/4.0

\section{REFERENCES}

1 Cruikshank RP, Stafford B, Jones L. Polypharmacy in the terminally ill. Med J Aust 2013;199:29.

2 Todd A, Nazar H, Pearson $\mathrm{H}$, et al. Inappropriate prescribing in patients accessing specialist palliative day care services. Int $J$ Clin Pharm 2014;36:535-43.

3 Kotlinska-Lemieszek A, Paulsen O, Kaasa S, et al. Polypharmacy in patients with advanced cancer and pain: a European cross-sectional study of 2282 patients. J Pain Symptom Manage 2014;48:1145-59.

4 McNeil MJ, Kamal AH, Kutner JS, et al. The Burden of Polypharmacy in Patients Near the End of Life. J Pain Symptom Manage 2016;51:178-83.

5 Dees MK, Geijteman ECT, Dekkers WJM, et al. Perspectives of patients, close relatives, nurses, and physicians on end-of-life medication management. Palliat Support Care 2018;16:1-10.

6 LeBlanc TW, McNeil MJ, Kamal AH, et al. Polypharmacy in patients with advanced cancer and the role of medication discontinuation. Lancet Oncol 2015;16:e333-e341.

7 Bemben NM. Deprescribing: An Application to Medication Management in Older Adults. Pharmacotherapy 2016;36:774-80.

8 van Nordennen RT, Lavrijsen JC, Vissers KC, et al. Decision making about change of medication for comorbid disease at the end of life: an integrative review. Drugs Aging 2014;31:501-12.

9 Lindsay J, Dooley M, Martin J, et al. The development and evaluation of an oncological palliative care deprescribing guideline: the 'OncPal deprescribing guideline'. Support Care Cancer 2015;23:71-8.

10 Lavan AH, Gallagher P, Parsons C, et al. STOPPFrail (Screening Tool of Older Persons Prescriptions in Frail adults with limited life expectancy): consensus validation. Age Ageing 2017;46:600-7.

11 Geijteman EC, Dees MK, Tempelman MM, et al. Understanding the continuation of potentially inappropriate medications at the end of life: perspectives from individuals and their relatives and physicians. J Am Geriatr Soc 2016;64:2602-4.

12 Paque K, Vander Stichele R, Elseviers M, et al. Barriers and enablers to deprescribing in people with a life-limiting disease: A systematic review. Palliat Med 2018:026921631880112.
13 Dutch College of General Practitioners (NHG). Multidisciplinary Polypharmacy Guideline for the elderly. Utrecht: Dutch College of General Practitioners, 2012.

14 de Graeff A, van Bommel JMP, van Deijck R. Palliatieve zorg, richtlijnen voor de praktijk. Utrecht: Comprehensive Cancer Centre the Netherlands, 2010.

15 Agora National Centre for Palliative Care. Factsheet Palliative care in the Netherlands, 2012.

16 Arevalo JJ, Geijteman ECT, Huisman BAA, et al. Medication use in the last days of life in hospital, hospice, and home settings in the Netherlands. J Palliat Med 2018;21:149-55.

17 Heppenstall CP, Broad JB, Boyd M, et al. Medication use and potentially inappropriate medications in those with limited prognosis living in residential aged care. Australas J Ageing 2016;35:E18-E24.

18 Geijteman ECT, Huisman BAA, Dees MK, et al. Medication discontinuation at the end of life: a questionnaire study on physicians' experiences and opinions. J Palliat Med 2018;21:1166-70.

19 Anderson K, Stowasser D, Freeman C, et al. Prescriber barriers and enablers to minimising potentially inappropriate medications in adults: a systematic review and thematic synthesis. BMJ Open 2014;4:e006544.

20 Reeve E, Bell JS, Hilmer SN. Barriers to optimising prescribing and deprescribing in older adults with dementia: a narrative review. Curr Clin Pharmacol 2015;10:168-77.

21 Bernacki RE, Block SD, American College of Physicians High Value Care Task Force. Communication about serious illness care goals: a review and synthesis of best practices. JAMA Intern Med 2014;174:1994-2003.

22 Jünger S, Payne SA, Brine J, et al. Guidance on Conducting and REporting DElphi Studies (CREDES) in palliative care: Recommendations based on a methodological systematic review. Palliat Med 2017;31:684-706.

23 Hasson F, Keeney S, McKenna H. Research guidelines for the Delphi survey technique. J Adv Nurs 2000;32:1008-15.

24 Todd A, Holmes HM. Recommendations to support deprescribing medications late in life. Int J Clin Pharm 2015;37:678-81.

25 Beers MH, Ouslander JG, Rollingher I, et al. Explicit criteria for determining inappropriate medication use in nursing home residents. UCLA Division of Geriatric Medicine. Arch Intern Med 1991;151:1825-32.

26 By the American Geriatrics Society 2015 Beers Criteria Update Expert Panel. American Geriatrics Society 2015 Updated Beers Criteria for Potentially Inappropriate Medication Use in Older Adults. J Am Geriatr Soc 2015;63:2227-46.

27 Gallagher P, Ryan C, Byrne S, et al. STOPP (Screening Tool of Older Person's Prescriptions) and START (Screening Tool to Alert doctors to Right Treatment). Consensus validation. Int J Clin Pharmacol Ther 2008;46:72-83.

28 Hanlon JT, Schmader KE, Samsa GP, et al. A method for assessing drug therapy appropriateness. J Clin Epidemiol 1992;45:1045-51.

29 Koekkoek JA, Postma TJ, Heimans JJ, et al. Antiepileptic drug treatment in the end-of-life phase of glioma patients: a feasibility study. Support Care Cancer 2016;24:1633-8. 